\title{
A RELEVÂNCIA DA COMPREENSÃO LEITORA E A COMPREENSÃO LEITORA PELA RELEVÂNCIA
}

\author{
Brendom da Cunha Lussani ${ }^{1}$ \\ Kári Lúcia Forneck ${ }^{2}$
}

\begin{abstract}
Resumo: Este trabalho pretendeu responder à seguinte questão norteadora: como potencializar práticas de ensino da compreensão leitora a partir da apropriação textual movida pela relevância? Para tanto, assumimos dois campos teóricos para concretizar uma interface: a Psicolinguística, no que diz respeito às estratégias de leitura, e a Pragmática, via Teoria da Relevância, no que diz respeito à busca pela relevância máxima da significação. Participaram da pesquisa quatro turmas de 80 ano de duas escolas da rede pública de duas cidades do Vale do Taquari-RS. A metodologia se concretizou pela proposição de intervenção didática a partir da leitura do texto Muribeca, de Marcelo Freire, tendo duas turmas como as de aplicação e duas como turmas de controle. As turmas de aplicação realizaram a leitura do texto com mediação do professor, o que não aconteceu nas turmas de controle. Os resultados obtidos nos testes de leitura que se seguiram às intervençóes revelaram que os alunos das turmas de aplicação obtiveram melhores desempenhos no que diz respeito ao processamento do significado. Evidenciou-se, assim, que as intervençôes didáticas de leitura, cujo foco era estimular a produção de inferências pela ativação de conhecimentos prévios e pela produção de prediçóes, auxiliam na busca pela relevância máxima nas tarefas de leitura. Ao fim, concluímos que é possível um trabalho em sala de aula tendo o significado do texto compreendido e processado pelos alunos, desde que o professor tenha em mente os objetivos de leitura e crie espaços de inferenciaçáo sobre o texto. Concretizamos, assim, a interface teórica intencionada neste estudo.
\end{abstract}

Palavras-chave: Compreensão leitora. Inferência. Ensino da leitura. Teoria da Relevância. Estratégias de leitura.

1 Mestrando do Programa de Pós-Graduação em Letras da PUCRS e professor de Língua Portuguesa da Rede Estadual do Rio Grande do Sul. bclussani@gmail.com.

2 Docente do Programa de Pós-Graduação em Ensino e do Curso de Letras da Universidade do Vale do Taquari - Univates. Doutora em Letras. kari@univates.br. 


\title{
RELEVANCE OF READING UNDERSTANDING AND READING UNDERSTANDING BY RELEVANCE
}

\begin{abstract}
This paper aims to answer the following guiding question: how to potentialize reading comprehension teaching practices from the relevance textual appropriation? Therefore, we assume two theoretical fields to concretize an interface: Psycholinguistics, regarding reading strategies, and Pragmatics, via Relevance Theory, regarding the search for the maximum relevance of meaning. Four 8th grade classes from two public schools in two cities of the Vale do Taquari-RS participated in the research. The methodology was materialized by the proposition of didactic intervention from reading the text Muribeca, by Marcelo Freire, having two classes as the application and two as control classes. The application classes read the text with the teacher's mediation, which did not happen in the control classes. The results obtained in the reading tests that followed the interventions revealed that the students of the application classes obtained better performances regarding the meaning processing. Thus, it was evidenced that the didactic reading interventions, whose focus was to stimulate the production of inferences through the activation of previous knowledge and the production of predictions, help in the search for maximum relevance in reading tasks. In the end, we conclude that it is possible to work in the classroom having the meaning of the text understood and processed by the students, provided that the teacher has in mind the reading goals and creates inferential spaces on the text. Thus, we concretize the theoretical interface intended in this study.
\end{abstract}

Keywords: Reading comprehension. Inference. Reading teaching. Relevance Theory. Reading strategies.

\section{Consideraçóes iniciais}

A compreensão leitora é uma habilidade essencial no ambiente social, uma vez que é por meio dela que podemos compreender os textos que nos cercam diariamente. A leitura - o decodificar, o compreender e o interpretar - é muitas vezes trabalhada em sala de aula, porém não de forma eficaz, como demonstram as avaliações de leitura em larga escala, das quais os alunos brasileiros participam, a exemplo do SAEB (Sistema Nacional de Avaliação da Educação Básica) e PISA (Programme for International Student Assessment). Os resultados obtidos nessas avaliações apenas comprovam o que muitos professores, em particular, e a sociedade, em geral, percebem: existe uma lacuna entre o que se lê e o que se compreende.

Por mais que a leitura, a compreensão e interpretação de textos sejam recorrentes nas aulas, em especial nas de Língua Portuguesa, os alunos brasileiros não a desenvolvem com qualidade. Essa carência na construção da compreensão do texto pode estar atrelada, entre outras razões, à forma como o professor conduz a leitura do texto e às estratégias de compreensão das quais os alunos se valem ao ler.

A compreensão de um texto está muito além das infinitas combinações de palavras e orações propriamente ditas. A compreensão se dá pela interação entre autor, leitor e texto. Para Leffa (1996), o leitor assume a posição de construtor, enquanto o autor é o arquiteto e o texto é a planta do prédio. Dada a ilustração, 
evidencia-se que o autor (engenheiro) sabe como o prédio ficará, ou seja, conhece o objetivo final do texto e seu significado; entretanto, cabe ao construtor, o leitor, ler a planta e construir o prédio tal como idealizado pelo arquiteto/autor. O processo de construção e idealização do prédio é o próprio ato de compreensão. Isso se dá porque, ao ler o texto, o leitor busca compreender as lacunas deixadas pelo autor, ativando, assim, informações que não estão presentes no texto que está sendo lido, mas informações que ele já conhece, processou e hoje as têm e que o ajudam a processar essa nova informação que é lida. Goodman (1991) já sinalizava que uma das características do texto é não ter significado, cabendo exclusivamente ao autor elaborar o texto de tal forma a conter um significado, que pode ser reconstruído pelo leitor. Assim, o significado final será uma construção das influências do autor, texto e leitor.

Entretanto, não são apenas os conhecimentos do leitor que o ajudam a construir esse novo texto, mas as marcas linguísticas que ali estão. Por marcas linguísticas compreendemos os elementos que fazem o texto ser um texto: as palavras, os recursos de pontuação, de coesão. Assim como o próprio leitor, as marcas linguísticas também se mostram fundamentais no que se refere à produção de sentido do texto, nos contextos de uso.

Um dos campos teóricos que tratam da produção de sentido da língua em contextos de uso é a Pragmática. Nessa perspectiva, visa-se a analisar como os discursos são produzidos e busca-se compreendê-los a partir da interação entre enunciador e interlocutor. É o que se propõe a Teoria da Relevância (SPERBER e WILSON, 1995), que parte do pressuposto de que, em contextos de interação linguística, processamos a linguagem de acordo com nossos interesses, que se fundamentam no ajustamento de conceitos novos e supostos já configurados em nossa memória linguística.

Neste estudo, procuramos compreender como é possível construir significados implícitos e explícitos, a partir de um contexto de ensino da leitura para alunos do $8^{\circ}$ ano de escolas públicas. Desse modo, intencionamos ilustrar uma ação pedagógica que pode tornar-se aliada do professor da Educação Básica para uma ação didática em que a compreensão seja potencializada.

Para a avaliação e a análise do percurso cognitivo da compreensão dos alunos participantes, optamos por construir uma interface teórica, entre campos linguísticos que, comumente, não dialogam. De um lado, utilizamos a Psicolinguística para desenhar a metodologia de desenvolvimento das propostas de intervenção e investigação para a compreensão textual, por meio do ensino de estratégias de leitura; do outro, usamos a Pragmática, subárea da Linguística, por meio da Teoria da Relevância, de Sperber e Wilson (1995), para descrever e explicar como se dá a produção de inferências a partir da percepção da relevância máxima do significado do texto.

Neste texto, apresentaremos como se deu a proposta e que resultados foram alcançados, com base em atividades de avaliação da compreensão leitora. Num primeiro momento, apresentaremos o percurso teórico que construímos na 
interface conceitual para, então, relatarmos como seu deu a proposta de investigação desenvolvida.

\section{0 ponto de vista da Psicolinguística: o que é necessário para a compreensão?}

A leitura é uma atividade complexa, que requer altas habilidades, que dependem de processos neurológicos ${ }^{3}$ e cognitivos. Dentre as habilidades cognitivas, algumas competências são consideradas sine qua non quando se fala em aprendizado da leitura e da compreensão.

Para Morais (2013), para que possamos compreender um enunciado são necessárias três habilidades: leitura fluente, identificação das palavras e conhecimentos prévios. Segundo o autor, é necessário ter fluência em leitura para que a compreensão seja construída, de modo que a atenção se foque no significado das palavras e não em sua decodificação ${ }^{4}$. Essa leitura rápida das palavras está diretamente ligada à segunda condição, a identificação das palavras. A respeito dessa condição, Morais (2013) afirma que:

O aluno que é perfeitamente hábil na identificação das palavras, ou seja, aquele que adquiriu completamente a técnica subjacente a essa habilidade, pode dedicar toda sua capacidade de tratamento consciente ao trabalho de compreensão. (MORAIS, 2013, p. 112)

Ao adotar essa perspectiva, o autor enfatiza que a compreensão se dá mediante uma elaboração mental, já que compreensão prevê processamento mental. Ao possuir total domínio da relação grafema-fonema e internalizá-la (tornando-a inconsciente), o leitor apodera-se dessa relação e a traz a compreensão para o plano consciente, sendo capaz de refletir sobre o que é lido.

Ainda segundo o autor, a compreensão do texto, além da leitura fluente e da identificação das palavras, requer que o leitor possua conhecimentos prévios, isto é, que já esteja relativamente familiarizado com a temática que é lida. Isso porque, ao ler, o leitor que já possuir algum conhecimento sobre o assunto conseguirá compreender melhor a nova informação; logo "quanto mais leitura, melhor a compreensão, e quanto melhor a compreensão, mais fácil parece a leitura e mais se lê" (MORAIS, 2013, p. 123).

Os estudos de José Morais corroboram com as pesquisas desenvolvidas por Isabel Solé (1998) sobre concepção de compreensão leitora. Os achados de Solé já evidenciavam que os conhecimentos prévios são fator decisivo para a compreensão do texto. A respeito dos conhecimentos prévios, Solé enfatiza que "[...] compreender não é questão de tudo ou nada, mas é relativa aos conhecimentos de que o leitor dispõe sobre o tema do texto [...]" (SOLÉ, 1998, p. 41). Isso porque

3 Recomendamos a leitura de Dehane (2012) para conhecer as bases neurológicas da leitura.

4 Em Dehaene (2012) há uma explicação interessante acerca das rotas de leitura - compreensão (rota semântica) e decodificação (rota fonológica). 
a compreensão do lido se dá mais facilmente se o leitor já possui conhecimentos básicos para compreender a nova informação.

Para poder ilustrar como os conhecimentos prévios se validam na leitura, consideramos a tirinha abaixo da Turma da Mônica (FIGURA 1). É importante lembrar que o gênero tirinha normalmente é de cunho humorístico, sendo que há uma quebra na lógica do discurso, em especial no último quadrinho que guarda o humor. Ademais, a tirinha é um gênero textual que não possui um grande conteúdo verbal, exigindo do leitor inferências, que requerem o uso do contexto para a compreensão e produção do humor.

Para pensarmos a relação dos conhecimentos prévios na compreensão do texto, observemos a tirinha abaixo:

Figura 1 - Magali vegetariana em "A Turma da Mônica"

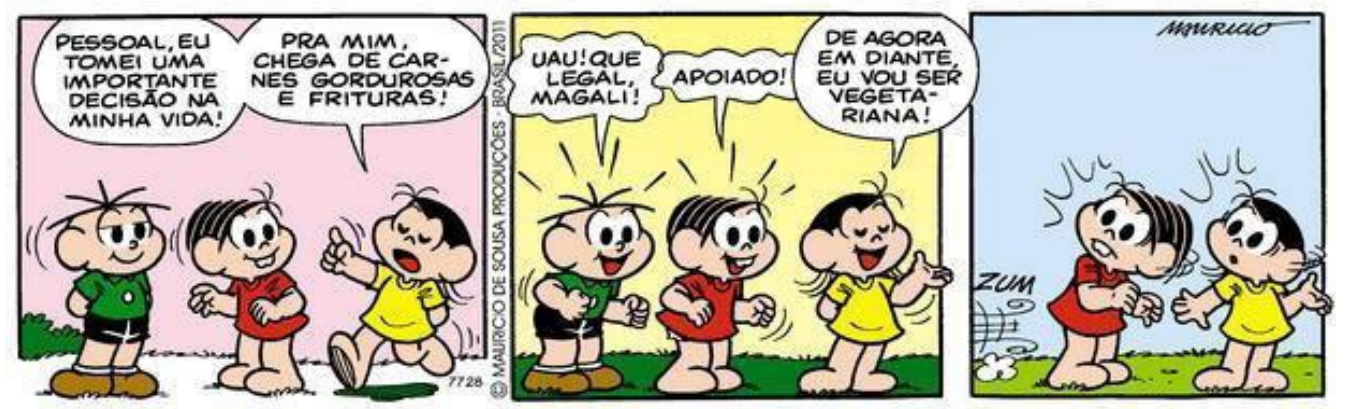

Fonte: Imagem da internet (2018).

Para que se cumpra o objetivo da tirinha, de fazer humor, é indispensável que o leitor resgate conhecimentos prévios. Propomos, aqui, uma análise possível para que a compreensão do humor se concretize. No contexto da tirinha, temos um trio de personagens, da Turma da Mônica, nacionalmente conhecidos, e cada um dispõe de uma característica que o particulariza. A personagem central dessa tirinha é a Magali, conhecida por ter um apetite insaciável. Quando a personagem avisa aos seus amigos de que deixará de comer alimentos que podem vir a causar algum problema de saúde, como carnes gordurosas e frituras, os amigos mostramse a favor da decisão. Entretanto, quando ela informa que para isso se tornará vegetariana, um de seus amigos, o Cebolinha, sai correndo, afastando-se das suas amigas.

Para que possa compreender a atitude de Cebolinha em afastar-se correndo das demais, logo após ter apoiado a atitude de uma delas, o leitor deverá acessar seus conhecimentos prévios, que podem ser:

(a) Magali se tornará vegetariana.

(b) Vegetarianos alimentam-se de alimentos de origem vegetal.

(c) Magali e Cebolinha são amigos. 
(d) Amigos andam juntos e/ou próximos.

(e) Cebolinha é um nome de um vegetal.

(f) Cebolinha é um alimento para os vegetarianos.

(g) Magali pode se alimentar de cebolinha, caso se torne vegetariana de fato.

(h) Cebolinha, homônimo do vegetal, sente-se ameaçado pelos novos hábitos alimentares de Magali.

(i) Cebolinha acredita que afastando-se da amiga pode evitar ser devorado.

A tirinha possibilita que o leitor produza as inferências de 1 (a-i) para que possa compreender o humor. Ou seja, requer que o leitor saiba o que é ser vegetariano, o que esse modo de se alimentar permite ingerir e que o nome de uma das personagens presentes na cena é Cebolinha, o mesmo nome dado a um vegetal, que integra o cardápio dos adeptos ao vegetarianismo.

Os conhecimentos necessários para produzir as inferências e poder gerar a compreensão a fim de atingir o humor proposto pela tirinha não emergem somente do texto, e sim dependem também do próprio leitor que antes desse texto, possivelmente, já havia interagido com outros textos do mesmo gênero e também dos mesmos personagens. E essa interação com outros textos que contribuiu para a formação de conhecimentos prévios acerca desse tema.

O exemplo acima evidencia o que Solé (1998) e Morais (2013) denominam de conhecimento prévio, sendo esse um aspecto essencial para a compreensão leitora. Solé afirma, ainda, que a compreensão e os conhecimentos prévios da temática lida são indissociáveis para que o leitor possa compreender o significado intencionado pelo autor do texto. A partir disso, a autora nos apresenta outro aspecto que é essencial para a compreensão: os objetivos da leitura.

Os objetivos de leitura, segundo Solé (1998), dizem respeito às motivações e intenções que direcionam a produção dos significados. A resposta à pergunta por que estou lendo este texto? implica a busca de recursos de natureza cognitiva, tais como a escolha de uma estratégia de leitura apropriada ao contexto. $\mathrm{O}$ uso da estratégia, por vezes, não se dá de forma consciente como o objetivo, porém é essencial no processamento da compreensão.

No que se refere a esse tema, a literatura especializada (KATO, 2007; LEFFA, 1996; SOLÉ, 1998) tem nos apresentado uma gama de estratégias de leitura de que o leitor se vale para atingir seus objetivos de leitura. As estratégias adotadas pelo leitor são de natureza cognitivas e metacognitivas. As estratégias cognitivas são as que o leitor realiza de forma intuitiva e inconsciente, como ler da esquerda para a direita, por exemplo; as estratégias metacognitivas, por sua vez, partem da tomada de consciência sobre o uso das primeiras, como a releitura de uma palavra ou frase mal compreendida.

Entre as estratégias metacognitivas estão a predição, a inferência, o automonitoramento, a autoavaliação e a autocorreção. Em Pereira (2012, p. 84), encontramos algumas dessas definições. Assim como a própria nomenclatura 
sugere, a predição é uma estratégia de leitura que pressupõe a antecipação da leitura, partindo dos conhecimentos prévios do leitor e das pistas linguísticas deixadas pelo autor no texto. A predição é uma estratégia de leitura que se concretiza simultaneamente às demais, especialmente à inferência que "ocorre entre uma afirmação inicial e uma afirmação final” (PEREIRA, 2012, p. 85). Sendo a predição a antecipação de informações, essa deve ser verificada pelo automonitoramento que, no avanço da leitura, auxilia na confirmação ou não das hipóteses elaboradas antes de a leitura iniciar de fato; havendo predições que podem provocar contradições internas, ocorre a autoavaliação, a partir da qual se pode continuar com a hipótese, ou se realiza uma autocorreção, a fim de promover a compreensão do lido (PEREIRA, 2012, p. 85).

As estratégias de leituras nem sempre são percebidas pelo leitor, entretanto ele as utiliza para fins de compreensão textual. Não existe um limite de estratégias a serem usadas por um leitor. O leitor faz uso das estratégias necessárias quando e como necessitar. As estratégias de leitura se mostram de suma importância no que se referem aos meios de atingir a relevância do que é lido, como veremos a seguir.

Nesta seção apresentamos os fundamentos da compreensão leitora à luz de pressupostos teóricos da Psicolinguística. Nesse campo teórico, a compreensão se dá pela concretização de estratégias de leitura, que, como elucidaremos na apresentação da proposta de investigação mais adiante, foram empregadas na concepção das atividades de intervenção didática.

\section{$2 \mathrm{O}$ ponto de vista da Pragmática: a relevância na produçáo de significado}

A Teoria da Relevância (TR), de Sperber e Wilson (1985, 1995), é um modelo teórico inferencial, que trata de descrever e explicar como se dá o processamento da linguagem humana no campo da Pragmática. Numa atualização de alguns dos pressupostos da Teoria das Implicaturas de Grice (1975), os autores argumentam, em linhas gerais, que a produção de significados é resultado de um processo inferencial que requer do leitor/ouvinte mais que a simples identificação do código linguístico. A TR parte da ideia de que os enunciados são processados considerando nossos próprios interesses e as intenções ostensivo-comunicativas por parte do falante. Como descrito pelos próprios autores:

Um comunicador codifica a mensagem pretendida dentro de um sinal, que é decodificado pela audiência por meio de uma cópia idêntica do código. De acordo com um modelo inferencial, um comunicador fornece evidência de sua intenção de comunicar um certo significado, que é inferido pela audiência com base na evidência fornecida. Um enunciado é, naturalmente, uma peça de evidência codificada linguisticamente, de modo que a compreensão verbal envolve um elemento de decodificação. Todavia, o significado linguístico decodificado é somente um dos inputs para um processo de inferência não demonstrativo que produz uma interpretação do significado do falante (WILSON e SPERBER, 2010, p. 221-222).

Dessa maneira, a TR busca explicar como a audiência infere, isto é, reconhece algo relevante a partir do enunciado produzido por um falante. Isso é possível, 
uma vez que todo enunciado cria no seu interlocutor uma expectativa a ser ou não certificada pelas e nas inferências (WILSON e SPERBER, 2010, p. 222). E essa expectativa é movida pela intenção de relevância máxima. Para Sperber e Wilson, a relevância é o ponto de equilíbrio entre efeitos cognitivos e esforços de processamento para a interpretação de informações nos contextos comunicativos (SILVEIRA e FELTES, 1999, p. 38).

Esse modelo inferencial prevê, ainda, que o leitor/ouvinte tomará como mais relevante o enunciado a respeito do qual ele já possui algum conhecimento, mesmo que haja outro input alternativo disponível ao mesmo tempo. Ou seja, "[...] intuitivamente, em contextos idênticos, quanto maior o valor das conclusões alcançadas pelo processamento de um input, mais relevante ele será" (WILSON e SPERBER, 2010, p. 224). Além disso, o input relevante oferece "uma diferença vantajosa na representação de mundo do indivíduo: uma conclusão verdadeira, por exemplo" (WILSON e SPERBER, 2010, p. 223).

Ou seja: quanto mais efeitos contextuais o leitor/ouvinte obtiver sobre determinado assunto e menor for o custo com esforços de processamento, maior será a relevância; em contrapartida, se o grau de estímulos contextuais for baixo e os esforços que o leitor/ouvinte tiver de destinar a processar a informação forem elevados, a relevância será baixa, conforme esquematizado na Figura 2:

Figura 2 - Efeitos cognitivos

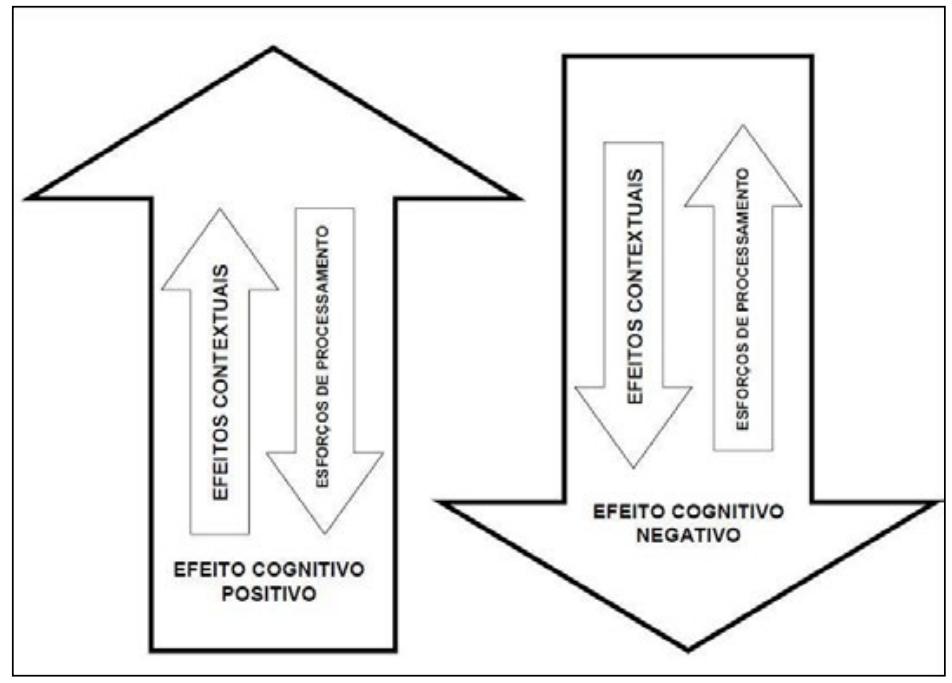

Fonte: Dos autores (2018).

O que determina a relevância de um estímulo em comparação a outro é a propriedade de gerar efeitos cognitivos na audiência. Em certos contextos, o mesmo estímulo pode ser mais ou menos relevante; os efeitos contextuais mais ou menos compreensíveis e um mesmo efeito cognitivo mais ou menos fácil ou difícil de perceber. Assim, "quanto maior for o esforço requerido de percepção, de 
memória e de inferência, menor será a recompensa pelo processamento do input e, por isso, um menor merecimento de atenção" (WILSON e SPERBER, 2010, p. 225).

Adotando a imagem acima (Figura 2), que esquematiza a relevância produzida a partir de um falante e tomando as proposições de Wilson e Sperber, temos como definir a Relevância de um input do seguinte modo:

a) "[...] quanto maiores forem os efeitos cognitivos positivos alcançados pelo processamento de um input, maior será a relevância do input para o indivíduo (WILSON e SPERBER, 2010, p. 225)".

b) "[...] quanto maior for o esforço de processamento despendido, menor será a relevância do input para um indivíduo (WILSON e SPERBER, 2010, p. 225)".

Wilson e Sperber (2010) ainda ampliam a ideia da existência de duas propriedades da comunicação humana: a comunicação ostensiva, vinculada ao enunciador, e a comunicação inferencial, vinculada ao ouvinte. De um lado, portanto, temos as intenções manifestas do falante e, de outro, o movimento inferencial do ouvinte. $\mathrm{E}$ ambos se comunicam no intuito de atingir a relevância máxima nos contextos comunicativos. A comunicação, portanto, deve ser planejada pelo falante a fim de que sua audiência a perceba, dadas às circunstâncias discursivas. Assim um enunciado ostensivo ocorre quando se mostra uma evidência direta das intenções do falante (SILVEIRA e FELTES, 1999, p. 38-39).

Vimos nesta seção os fundamentos da TR, que tratam de elucidar como se dão as relações custo-benefício para a produção de significado, na busca da relevância máxima. A seguir, apresentaremos os resultados encontrados, a fim de concretizarmos a interface intencionada neste estudo.

\section{Metodologia}

A interface aqui pretendida, a partir de uma abordagem didático-pedagógica amparada, de um lado, nos pressupostos da Psicolinguística e, de outro, na Teoria da Relevância (TR), busca contribuir para a composição do significado do texto em sala de aula.A partir da apropriação da temática e das estratégias investigativas que ambos os campos teóricos vêm desenvolvendo, organizou-se uma intervenção didática, ancorada em ambos os pressupostos teóricos, a partir da leitura do texto Muribeca, de Marcelino Freire (2000).

A proposta didática consiste na análise dos resultados de testes de leitura de quatro turmas, do $8^{\circ}$ ano do Ensino Fundamental, de duas escolas distintas (Escola A e Escola B). Todos os participantes, num total de 63 educandos, estavam matriculados e frequentavam a escola, no oitavo ano, no momento da realização deste estudo. As idades dos alunos variaram de 13 a 16 anos. Os pais e responsáveis pelos estudantes assinaram o termo de consentimento livre e esclarecido e os alunos assinaram o termo de assentimento para a concretização deste teste de leitura. Em cada espaço educacional foram avaliadas duas turmas, uma sendo o grupo de 
aplicaşão e a outra o grupo de controle: na Escola A, participaram 46 alunos, sendo que a turma de aplicação contou com 22 alunos e a turma de controle, 24; na escola B, participaram 17 alunos, sendo 8 da turma de aplicação e 9 da turma de controle.

Em ambas as escolas, as turmas foram expostas a duas metodologias de ensino da leitura distintas para o mesmo texto. Em um dos cenários de leitura, (a) o professor mediou a leitura intervindo com questões que ativassem conhecimentos prévios que poderiam facilitar a compreensão do texto; no segundo, (b) o professor apenas ofertou o texto e solicitou que cada aluno realizasse a leitura de forma individual e silenciosa. Nos grupos de aplicação, portanto, o professor mediador ajudou na leitura do texto, fazendo as intervenções propostas por esta pesquisa; já nos grupos de controle, apenas se ofertou o texto aos alunos, que tiveram que ler e compreendê-lo a partir de seus esforços individuais. Quanto às questões, o professor não auxiliou nenhum dos grupos, nem no que diz respeito a ler e compreender o que elas solicitaram.

A intervenção do mediador realizada no cenário a compartilhou tanto dos princípios de uma enunciação ostensivo-inferencial (WILSON; SPERBER, 2010), quanto dos pressupostos do processamento da compreensão leitora no campo da Psicolinguística, já que intencionou uma abordagem de compreensão dos implícitos do texto pela produção de estratégias de leitura, tais como a ativação de conhecimentos prévios e automonitoramento. As intervenções consistiram em perguntas realizadas durante a leitura, que tinham relação semântica com as questões de compreensão a que os alunos deveriam responder em seguida e que tinham o intuito de fazer com que os alunos pensassem sobre o conteúdo lido. As intervenções estão explicitadas abaixo: 
Figura 1 - Texto Muribeca com as indicações das intervenções de leitura

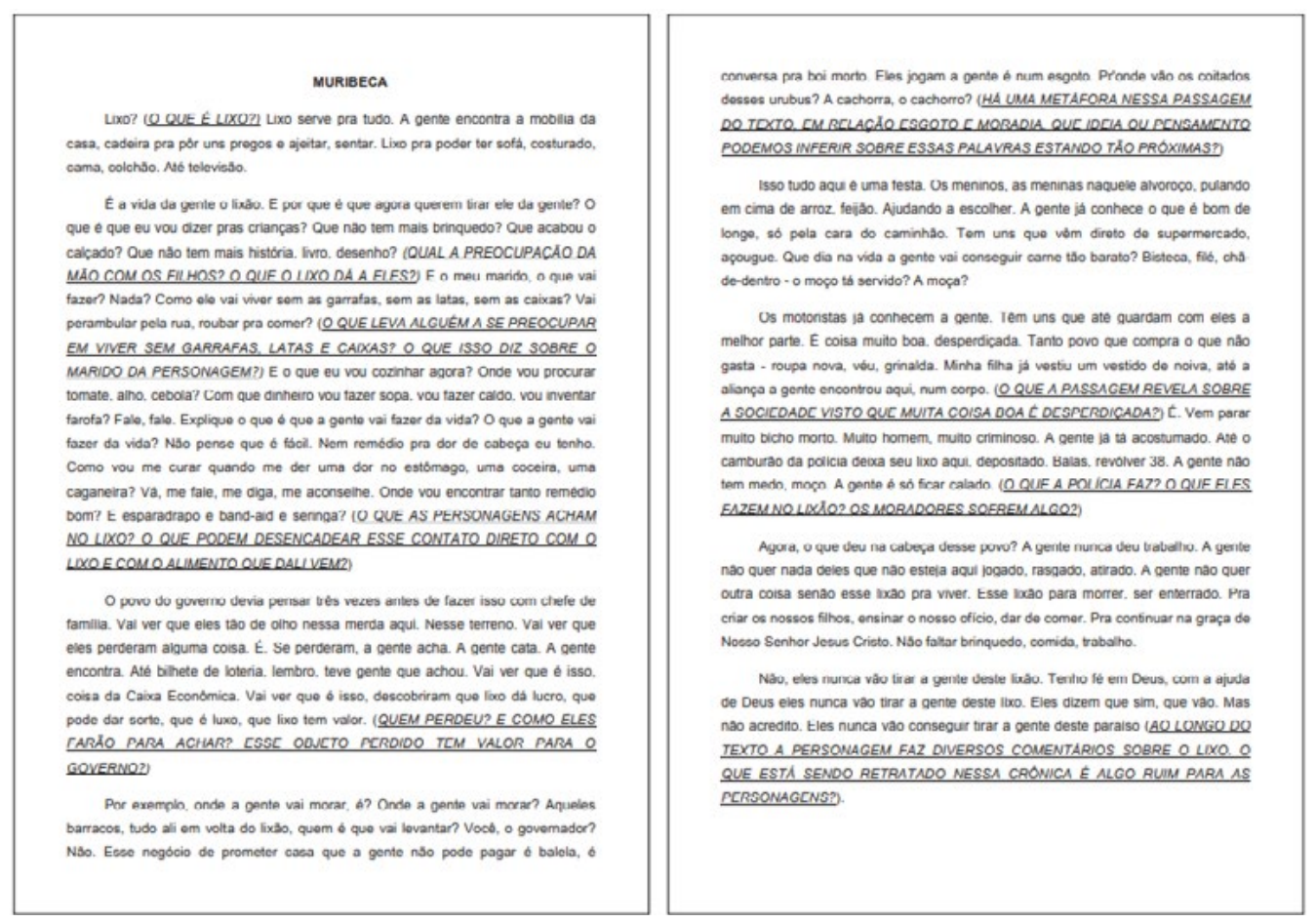

Fonte: Freire (2000), adaptado

Em ambos os cenários, após a leitura, os textos foram recolhidos e, em seguida, os alunos receberam um questionário contendo oito perguntas, tendo como respostas duas opções sim e não, acrescidas de: estou certo dessa resposta e não tenho certeza quanto a essa resposta, tendo em vista o propósito de verificar se o aluno havia processado as informações mais relevantes durante a leitura para que se pudesse verificar se o aluno tinha ou não certeza do que estava respondendo, indicando a precisão da resposta dada à pergunta. $\mathrm{O}$ uso do recurso da precisão da resposta dada é uma forma de fazer com que os alunos pensassem no que estavam respondendo. Os participantes, tanto do cenário $a$ quanto no $b$, não foram auxiliados pelo mediador no momento de responder às questões.

\section{Resultados}

Nesta seção serão apresentados os resultados obtidos durante a investigação. Todos as respostas foram consideradas para a análise. Os resultados serão apresentados em duas etapas: num primeiro momento, serão apresentados os achados obtidos na Escola $\mathrm{A}$ e, num segundo momento, serão apresentados os achados obtidos na Escola B, como se segue. 


\subsection{Resultados da Escola A}

Expomos agora os resultados encontrados na escola A. Para esta investigação, participaram 46 alunos, sendo 22 alunos da turma de aplicação e 24, da turma de controle. $\mathrm{O}$ teste realizado na Escola A evidenciou o que se esperava, considerando os campos teóricos em análise: o conhecimento prévio auxilia na compreensão do texto, de modo a contribuir para a busca da relevância máxima na produção do significado.

Para a ilustração dos achados do teste na Escola A, transcrevemos na Tabela 1 os resultados do teste de leitura:

Tabela 1 - Dados Escola A

\begin{tabular}{|c|c|c|c|c|}
\hline \multirow{2}{*}{ QUESTÕES } & \multicolumn{2}{|c|}{ APLICAÇ̃̃O } & \multicolumn{2}{c|}{ CONTROLE } \\
\cline { 2 - 5 } & ACERTO & ERRO & ACERTO & ERRO \\
\hline 1 & 14 & 8 & 12 & 12 \\
\hline 2 & 20 & 2 & 22 & 2 \\
\hline 3 & 7 & 15 & 10 & 14 \\
\hline 4 & 12 & 10 & 14 & 10 \\
\hline 5 & 5 & 17 & 5 & 19 \\
\hline 6 & 20 & 2 & 16 & 8 \\
\hline 7 & 22 & 0 & 18 & 6 \\
\hline 8 & 16 & 6 & 9 & 15 \\
\hline TOTAL & $\mathbf{1 1 6}$ & $\mathbf{6 0}$ & $\mathbf{1 0 6}$ & $\mathbf{8 6}$ \\
\hline TOTAL DE ACERTOS POSSÍVEIS & $\mathbf{2 2}$ alunos & $\mathbf{2 4}$ alunos \\
\hline PERCENTUAL DE ACERTO & \multicolumn{3}{|c|}{$\mathbf{6 5 , 9 1 \%}$ possíveis } & $\mathbf{1 9 2}$ acertos possíveis \\
\hline DIFERENÇA & \multicolumn{5}{|c|}{$\mathbf{5 5 , 2 1 \%}$} \\
\hline
\end{tabular}

Fonte: Dos autores (2018)

O teste era composto por oito questões a partir da leitura do texto Muribeca, como já explicado na seção da metodologia. $\mathrm{O}$ total de acertos possíveis para o grupo de aplicação era de 176; e para o grupo controle, 192. O grupo de aplicação obteve 119 acertos e o grupo de controle, 106 acertos.

Em ambos os grupos, a questão 3, "O texto fornece pistas que indicam que os filhos, mesmo marginalizados, são leitores?”, e a questão 5, “A personagem supõe que o lixo não tem valor para o governo?”, foram aquelas em que os erros sobressaíram-se em relação à parcela de acertos. Para a questão 3, duas perguntas foram feitas na intervenção, a fim instigar a reflexão: "Qual a preocupação da mãe com os filhos? O que o lixo dá a eles?". Uma interpretação possível é de que os alunos não compreenderam a quem se referia o anafórico (eles) na pergunta de intervenção, não notando que se falava sobre os filhos e não eles no sentido amplo, abarcando toda a família. Além da 
possível complicação de perceber a quem se referia o pronome, a sequência de palavras história e livro, que dá origem à pergunta e à resposta, está numa sequência de questionamentos proposto pelo texto original "[...] E por que é que agora querem tirar ele da gente? O que é que eu vou dižer pras crianças? Que não tem mais brinquedo? Que acabou o calçado? Que não tem mais história, livro, desenho?". A intervenção proposta foi feita logo após a leitura do último questionamento do próprio texto e pode ter levado os alunos a pensarem que os filhos somente brincavam, coloriam, mas não liam. Ainda é possível, também, inferir que os participantes tenham visto esta possibilidade, pois creram que no contexto em que viviam as crianças não poderiam saber ler. Nas opções que seguiam o sim e não, quatorze alunos marcaram a opção "Não tenho certeza quanto a essa resposta". Entre esse número de alunos que respondeu à questão e sinalizou que não tinha total certeza do que respondia, apenas quatro acertaram a resposta. Fica evidente, então, que a intervenção realizada para esta questão durante a leitura não foi suficiente para que os participantes produzissem a inferência sobre o lido, ou seja, os estímulos promovidos durante a leitura não se configuraram supostos relevantes para que os alunos percebessem a significação certa: a de que, mesmo vivendo num ambiente marginalizado, os filhos da personagem são leitores.

A segunda questão em que o número de erros superou o de acertos, como apresentado anteriormente, foi a questão 5 , “A personagem supõe que o lixo não tem nenhum valor para o governo?”. Nesta pergunta, dezessete alunos da turma de aplicação erraram e apenas cinco a acertaram. Durante a leitura da passagem: "[...] Até bilhete de loteria, lembro, teve gente que achou. Vai ver que é isso, coisa da Caixa Econômica. Vai ver que é isso, descobriram que lixo dá lucro, que pode dar sorte, que é luxo, que lixo tem valor", fizeram-se as seguintes intervenções: "Quem perdeu? E como eles farão para achar? Esse objeto perdido tem valor para o governo?”.

As intervenções propostas após a passagem, que remetiam diretamente à questão 5, foram claras e levavam o aluno a pensar sobre a passagem que acabara de ler. Entretanto, não foi trabalhada, durante a leitura com os alunos, uma oposição de raciocínio dentro do enunciado, como é visto na pergunta. A presença do não na questão sobre o texto (A personagem supõe que o lixo $\mathrm{N} \tilde{A O}$ tem nenbum valor para o governo?) quebra a lógica de um pensamento que construiu uma resposta diante de um sim nas intervenções. Podemos afirmar isso, pois, no grupo que errou a questão, dos dezessete, dez afirmaram ter certeza quanto à resposta que emitiram, cinco apresentaram dúvidas e dois não marcaram certeza nem dúvida. Dos cinco alunos que acertaram a questão, quatro demonstraram total certeza quanto à resposta que emitiram e apenas um não tinha certeza. Podemos entender que esses cinco alunos inferiram que a lógica construída durante a leitura era diferente da solicitada na resposta da questão. Percebe-se que as questões tidas como dificeis não são de fato difíceis, se analisadas e percebidas como falhas do próprio instrumento de pesquisa. Sendo que na primeira questão (3) há que se considerar a construção subjetiva a respeito de ser ou não ser leitor, a partir de conhecimentos prévios do que é ser leitor. No segundo caso (5), há um pensamento lógico a que os alunos, ao menos durante esta leitura, não haviam sido expostos, dificultando o processamento do 
enunciado da questão. Esse resultado evidencia que questões que quebram a lógica do raciocínio já pré-construído tendem a apresentar respostas insatisfatórias.

Nas demais questões, a relação acerto versus erro, não apresentou grande distanciamento entre os achados, porém o grupo de aplicação errou menos em relação ao grupo controle. $\mathrm{O}$ grupo de aplicação não apresentou uma vantagem grande em relação ao grupo controle, porém errou menos, e isso pode ser explicado pela mediação do professor. Nota-se que o grupo de aplicação obteve um percentual de acertos de $65,91 \%$ e, quando comparado ao grupo controle, temse uma diferença de $10,7 \%$ a mais, visto que a porcentagem de acertos das questões sobre o texto do grupo controle foi de $55,21 \%$.

Os resultados encontrados na tabulação das respostas dos participantes evidenciaram que houve efeitos cognitivos positivos durante a leitura do texto. Assim, quando confrontados com questionamentos sobre o texto, os alunos do grupo de aplicação, que foram conduzidos em suas leituras por questões norteadoras que estavam interligadas às questões da investigação, conseguiram obter um melhor desempenho na produção de inferências, isto é, o lido e debatido, antes dos questionamentos, mostrou-se decisivo para construir o significado. Os estímulos iniciados pelo mediador no decorrer da leitura foram mais relevantes que outros estímulos que poderiam surgir a partir da leitura individual, resultando em efeitos cognitivos positivos, logo, acertos.

As questões 1, 5, 6, 7 e 8 do questionário, foram aquelas em que o grupo de aplicação se destacou em relação ao grupo controle. Entendemos que nessas questões os alunos conseguiram obter a relevância máxima a partir do que os enunciados das questões solicitavam. Esse processamento, em nosso entender, decorreu da estratégia de leitura adotada por esta investigação, visando aos efeitos cognitivos positivos a partir das intervenções ao longo do texto.

As intervenções, que ajudavam a despertar os conhecimentos prévios dos alunos para solucionar as questões que viriam depois, foram responsáveis por criar uma ponte entre o que se lia e o que se questionava, não deixando os alunos sem uma base de conhecimentos para responderem às questões futuras. Assim, como prevê a TR, as discussões prévias às questões vieram suprir algumas expectativas futuras dos alunos que fariam uso delas na resolução das questões de leitura e, a partir delas, buscariam a máxima relevância, ou seja, descartariam estímulos que não haviam sido mencionado para selecionar o que melhor se adaptasse aos debates anteriores às questões.

Para que se possa evidenciar esse fato, analisemos a questão 7: O marido e a mulher se caracterizam como trabalhadores do lixo, ou seja, eles são catadores?. Esta questão todos os alunos que participaram do grupo de aplicação acertaram. Entre eles, dezesseis tiveram total certeza da sua resposta, quatro apresentaram dúvidas e dois não sinalizaram nenhuma opção. Na passagem " $E$ o meu marido, o que vai faz̧er? Nada? Como ele vai viver sem as garrafas, sem as latas, sem as caixas? Vai perambular pela rua, roubar pra comer?" que remetia à questão 7, foram feitas as duas seguintes intervenções: O que leva alguém a se preocupar em viver sem garrafas, latas e caixas? O que isso diz sobre o 
marido da personagem?. Essas intervenções permitiram aos alunos inferir que eles, o marido e a personagem narradora, eram catadores de lixo.

A pergunta e a resposta não são óbvias, visto que a intervenção se mostrou um diferencial para o resultado final. A mesma questão, porém, no grupo controle, contou com dezoito acertos e seis erros. Do grupo de alunos que acertaram, treze tinham certeza de que a sua resposta era correta, três apresentaram dúvida e dois não sinalizaram. Evidencia-se que a intervenção ampliou a compreensão e a produção de significado mais relevante. No que diz respeito ao percentual de certeza da questão 7 , o grupo de aplicação teve um total de $72,72 \%$ confiança da sua resposta, já o grupo controle, que não se apresentou numa totalidade de acertos, teve $72,22 \%$ de certeza da sua resposta. Assim, mesmo que a questão se mostre fácil, aos que não acertaram, a intervenção se caracterizaria como peça fundamental para a resolução.

A questão 8, As personagens são oprimidas, inclusive, pela polícia?, foi a que teve maior diferença entre os grupos. No grupo de aplicação, 16 alunos acertaram; no grupo de controle, 9 conseguiram perceber o implícito no texto. A questão 8 foi, de antemão, considerada uma das mais complexas pelos pesquisadores, pois exigia um nível de compreensão que dependia, exclusivamente, da leitura nas entrelinhas, dos conhecimentos prévios do leitor, do contexto e de uma possível inferência global da temática do texto.

Durante a passagem do texto "[...] É. Vem parar muito bicho morto. Muito homem, muito criminoso. A gente já tá acostumado. Até o camburão da polícia deixa seu lixo aqui, depositado. Balas, revólver 38. A gente não tem medo, moço. A gente é só ficar calado"., o grupo de aplicação contou com os seguintes questionamentos que os auxiliaram a compreensão da questão: O que a polícia faz? O que eles fazem no lixão? Os moradores sofrem algo?. Essas três intervenções, que conforme apontam os resultados de acertos, constituíram-se perguntas que fizeram diferença para a compreensão da passagem. Para os que acertaram a questão, 8 participantes apontaram que tinham certeza da resposta que estavam emitindo, 7 tinham dúvidas sobre a resposta sim e um não respondeu à questão quanto à certeza da resposta. Já para o grupo que errou a questão, um total de 6 alunos, 4 se mostraram incertos quanto à resposta não e 2 duvidaram de suas respostas.

Diante dessa análise, vê-se que as intervenções permitiram um grande número de alunos inferirem que $\operatorname{sim}$, as personagens eram oprimidas, inclusive, pela polícia. Este fato se dá pelo número de alunos que acertaram a pergunta, no grupo de aplicação, e a incerteza quanto à resposta não encontrada no grupo controle. As intervenções podem nem sempre estimular o leitor à construção de uma base de raciocínio e pensamento para que se responda a uma questão ou subsidiar conhecimentos prévios, para que esse infira sobre algo. Porém, elas permitem que ele se questione, se analise e se reflita sobre o que se lê e se tome como verdade o estímulo que despertar o maior número de efeitos contextuais.

Nessa questão, mais especificamente, podemos evidenciar que as ideias e propostas apontadas por Solé (1998), Morais (2013) e pela TR, acerca da produção de inferências, são evidentes em nossa análise. Isso se dá, pois a estratégia de leitura 
utilizada nessa experimentação didática permite o aluno leitor inferir significados do texto, propondo expectativas que são sancionadas ao longo do diálogo entre os pares e pelo próprio texto.

A condução da leitura do texto, com interferências, se mostrou facilitadora e auxiliou os alunos a refletirem sobre o texto e os enunciados que poderiam passar despercebidos e que posteriormente seriam revistos no questionamento. Como evidenciamos, quando a intervenção se mostrou falha ou fraca para conduzir a uma inferência e fazer com que os conhecimentos dos alunos fossem ampliados ou estimulados, o aluno errou a questão e apresentou desconfiança quanto a resposta que emitia. Isso pôde ser evidenciado nas questões 3 e 5, como já discutido anteriormente, reiterando que as interferências se constituíram de pausas eficazes para que se compreendesse o que era lido.

As intervenções propostas foram cuidadosamente selecionadas para que não ocorresse quebra da coerência do texto e fosse respeitada a mensagem pretendida pelo autor. O cuidado para a realização das interferências no fluir da leitura pode ser notada na questão 1, O texto faz. uma crítica ao uso indevido do lixo como forma de sobrevivência?. Para essa questão, optou-se em intervir ao final do texto, quando já concluída toda a leitura, pois se propôs aos alunos o seguinte estímulo: Ao longo do texto a personagem faz diversos comentários sobre o lixo. O que está sendo retratado nessa crônica é algo ruim para as personagens?. A intervenção, no próprio enunciado, sinaliza a crônica como sendo produto de uma leitura já concluída, logo aparece sendo a última intervenção, mas recompensa o leitor por ser a primeira questão, aquela a que talvez não seria dada tanta atenção pelo leitor se fosse abordada no início da leitura. As demais questões foram organizadas a partir da aparição de seus fragmentos, que lhes davam origem. Esse processo foi importante, pois o significado do texto foi sendo construído à medida que o lido anterior era processado, compreendido e debatido, não ficando lacunas a serem preenchidas somente no final da leitura. Buscamos, assim, construir os significados a cada momento de intervenção.

Com exceção das questões 2 e 4, os acertos do grupo de aplicação foram superiores aos acertos do grupo controle. A questão 2, $O$ texto pretende criticar o governo e suas promessas de saneamento básico não cumprida?, é originada a partir do fragmento: "[...] Por exemplo, onde a gente vai morar, é? Onde a gente vai morar? Aqueles barracos, tudo ali em volta do lixão, quem é que vai levantar? Você, o governador? Não. Esse negócio de prometer casa que a gente não pode pagar é balela, é conversa pra boi morto. Eles jogam a gente é num esgoto. Pronde vão os coitados desses urubus? A cachorra, o cachorro?’. Para que os enunciados fossem levados à relevância máxima do significado pretendido pelo autor, estimulou-se os alunos através da seguinte pergunta: Há uma metáfora nessa passagem do texto, em relação ao esgoto e moradia. Que ideia ou pensamento podemos inferir sobre essas palavras estando tão próximas? No cenário de leitura do grupo de aplicação, 22 alunos acertaram a questão, porém 11 desses se mostraram indecisos em relação à resposta que estavam emitindo, 7 mostraram-se certos, 2 marcaram, respectivamente a relação: resposta errada e certo da sua resposta e com dúvida quanto a sua resposta. Para o grupo controle, a mesma questão foi respondida de forma correta por todos os participantes, resultando em: 11 alunos com total certeza 
do que respondia, 7 acertos com ressalvas e 6 que não marcaram nenhuma opção. Esse número expresso dos erros do grupo de aplicação, acrescido da análise das incertezas quanto às respostas que emitem, pode ser atribuída à intervenção dada para este tópico. A expressão metáfora, utilizada na intervenção (Há uma metáfora nessa passagem do texto, em relação ao esgoto e moradia. Que ideia ou pensamento podemos inferir sobre essas palavras estando tão próximas?), pode ter sido a geradora de dúvida entre os participantes que, talvez, por não saberem o que é metáfora, acharam que poderia ser uma questão falsa, ou seja, uma questão que buscava confundi-los, causando assim um empecilho para que atribuíssem maior relevância a um dos estímulos dados.

No que se refere à questão $4, O$ texto faz. uma denúncia e expõe indiretamente o consumismo da sociedade urbana?, o grupo controle também conseguiu utilizar-se apenas dos estímulos dados pelo próprio texto, ficando o grupo de aplicação sem a clareza do estímulo que os conduziria à resposta certa. Durante a leitura, o grupo de aplicação recebeu como estímulo o questionamento: $O$ que a passagem (do texto original) revela sobre a sociedade, visto que muita coisa boa é desperdicada?. Dos 12 participantes que acertaram a resposta, 6 marcaram certeza e 6 marcaram desconfiança de suas respostas. Dos que erraram, um total de 10 alunos, 5 mostraram-se incertos da resposta, 4 mostraram-se seguros em emitir uma negativa e 1 não sinalizou a sua escolha. Nota-se que o estímulo dado foi o correto, pois, levou a maior parcela de alunos que errou a questionar a veracidade das suas respostas.

A proposta dessa seção foi de analisarmos os dados encontrados na Escola A e explicar o porquê das respostas encontradas, tanto as respostas em que o grupo de aplicação mostrou encontrar a relevância máxima pretendida pelos estímulos, quanto quando não encontrou o estímulo certo que os levaria à resposta correta. Outro aspecto que evidenciamos, ao longo desta discussão, foi a importância da estratégia de leitura que a proposta didática fez uso. Possivelmente, se tais intervenções tivessem sido feitas todas ao término da crônica ou se se fizessem as perguntas antes do início da leitura, os dados aqui apresentados seriam outros e a análise também poderia pautar-se em outros aspectos.

Após a análise dos dados da Escola $A$, analisemos os dados encontrados na Escola B.

\subsection{Resultados da Escola B}

A partir da aplicação dos testes na Escola B, obtivemos os seguintes dados: Tabela 3 - Dados Escola B

\begin{tabular}{|c|c|c|c|c|}
\hline \multirow{2}{*}{ QUESTÕES } & \multicolumn{2}{|c|}{ APLICAÇ̃̃O } & \multicolumn{2}{c|}{ CONTROLE } \\
\cline { 2 - 5 } & ACERTO & ERRO & ACERTO & ERRO \\
\hline 1 & 0 & 8 & 3 & 6 \\
\hline 2 & 7 & 1 & 6 & 3 \\
\hline 3 & 3 & 5 & 1 & 8 \\
\hline
\end{tabular}




\begin{tabular}{|c|c|c|c|c|}
\hline \multirow{2}{*}{ QUESTÕES } & \multicolumn{2}{|c|}{ APLICAÇÃO } & \multicolumn{2}{c|}{ CONTROLE } \\
\cline { 2 - 5 } & ACERTO & ERRO & ACERTO & ERRO \\
\hline 4 & 8 & 0 & 7 & 2 \\
\hline 5 & 2 & 6 & 2 & 7 \\
\hline 6 & 7 & 1 & 6 & 3 \\
\hline 7 & 7 & 1 & 7 & 2 \\
\hline 8 & 6 & 2 & 5 & 4 \\
\hline TOTAL & $\mathbf{4 0}$ & $\mathbf{2 4}$ & $\mathbf{3 7}$ & $\mathbf{3 5}$ \\
\hline TOTAL DE ALUNOS & $\mathbf{8}$ alunos & $\mathbf{9}$ alunos \\
\hline TOTAL DE ACERTOS POSSÍVEIS & $\mathbf{6 4}$ possíveis acertos & $\mathbf{7 2}$ possíveis acertos \\
\hline PERCENTUAL DE ACERTO & \multicolumn{3}{|c|}{$\mathbf{6 2 , 5}$} & $\mathbf{5 1 , 4}$ \\
\hline DIFERENÇA & \multicolumn{5}{|c|}{} \\
\hline
\end{tabular}

Fonte: Dos autores (2018)

Os achados na Escola B assemelham-se muito aos resultados visto na Escola A. A pergunta 3 (O texto fornece pistas que indicam que os filhos, mesmo marginalizados, são leitores?), voltou a ser uma pergunta em que o número de erros se sobressaiu em relação ao número de acertos. A questão 5 (A personagem supõe que o lixo não tem nenhum valor para o governo?), também é percebida, novamente, como uma questão em que os alunos não conseguiram inferir a resposta a partir dos estímulos propostos na intervenção e chegar à relevância máxima para acharem a resposta correta.

Todavia, diferente da Escola B, para estes dois grupos pesquisados, a questão 1, O texto faz. uma crítica ao uso indevido do lixo como forma de sobrevivência?, também gerou dificuldades de processamento. Dos 17 participantes, 14 erraram a questão e 5 acertaram. No grupo dos que acertaram, todos marcaram que estavam certos dessa resposta; em comparação aos que erraram, 6 sinalizaram estarem certos quanto à resposta, 5 apresentaram incerteza e 3 não marcaram nenhuma opção. O estímulo fornecido para todo o grupo de aplicação foi o comentário realizado no final da leitura do texto: Ao longo do texto a personagem faz diversos comentários sobre o lixo. $O$ que está sendo retratado nessa crônica é algo ruim para as personagens?. Se para o grupo da Escola A o estímulo conseguiu conduzir à inferenciação de achar a resposta certa para o questionamento, isso não ocorreu para o grupo da Escola B. Mesmo o contexto linguístico sendo o mesmo, o ambiente escolar é outro, os participantes se constituem diferentes, o que, em nosso entender, também pode ser visto como fator que intervém no resultado final.

Nas questões que seguem, os resultados encontrados na Escola B se assemelham aos resultados encontrados na escola anterior. Percebemos, assim, que as interferências propostas pela investigação, por meio da estratégia de leitura de questionar o leitor ao longo do texto, mostraram-se eficazes no que diz respeito à compreensão do texto, uma vez que os alunos conseguiram atribuir um significado ao que estava sendo lido. 
Os achados neste trabalho também confirmam que é possível chegar à relevância máxima do texto, por meio de propostas pedagógicas que conduzam o aluno à produção de inferências. De um lado, portanto, a compreensão leitora se concretiza por meio da concretização de estratégias de leitura, como a ativação de conhecimentos prévios e a predição - propostas nas atividades de intervenção - e por meio da busca da relevância máxima no processamento da significação, com baixo custo e alto benefício.

\section{Consideraçóes finais}

Pretendíamos aqui elucidar uma interface teórica entre Psicolinguística e Pragmática, na promoção da leitura. Ao longo da análise dos achados da investigação, ficou evidente que esta abordagem metodológica e epistemológica é possível e que os alunos que participaram das intervenções de leitura prévias ao teste, conseguiram inferir os enunciados e selecionar a relevância que vinha ao encontro das questões solicitadas, em especial o grupo de aplicação. Entendemos que esse fato decorre, por sua vez, da estratégia de leitura que esta proposta didática oportunizou aos participantes.

Chamamos a atenção ao fato de que a leitura, quando possui objetivos, desde a apresentação do texto, a forma como ele é lido e trabalhada em sala de aula, pode trazer benefícios ao aluno. Concordamos com os teóricos da Relevância, para quem "todo processamento de informação exige algum esforço" (SILVEIRA e FELTES, 1999, p. 44) e, em nosso entender, quando os esforços são alcançados e satisfeitos por quem os processa, resultam em efeitos cognitivos, como evidenciamos nos achados dos grupos de aplicação das Escolas A e B.

Ao fim desta investigação, fica evidente que o professor tem uma influência direta na leitura de texto e que a produção de inferências, a partir de estímulos oriundos do próprio texto, com auxílio do professor, possibilita uma compreensão maior do texto.

\section{Referências}

GABRIEL, Rosângela. A compreensão em leitura enquanto processo cognitivo. Signo, Santa Cruz do Sul, ago. 2008. ISSN 1982-2014. Disponível em: < https://online.unisc.br/ seer/index.php/signo/article/view/441>. Acesso em: 11 nov. 2019.

GOLDNADEL, Marcos; OLIVEIRA, Rita de Cássia. Contribuições da Teoria da Relevância para a prática de interpretação de textos: uma ilustração por meio de textos de humor. Linguagem \& Ensino, 2009. Vol.12, n.1, p.33-48.

GOODMAN, K. S. Unidade na leitura - um modelo psicolinguístico transacional. Letras de Hoje, v. 26, n. 4, p. 9-43, dez. 1991.

KATO, M. A. O aprendizado da leitura. São Paulo: Martins Fontes, 2007. 
LEFFA, V. Aspectos da leitura: uma perspectiva psicolinguística. Porto Alegre: Sagra, 1996.

MORAIS, José. Alfabetizar para a democracia. Porto Alegre: Penso, 2014.

Criar leitores: para professores e educadores. São Paulo: Minha Editora, 2013.

ORGANIZAÇÃO PARA A COOPERAÇÃO E DESENVOLVIMENTO

ECONÔMICO (OCDE). Brasil no PISA 2015: análises e reflexões sobre o desempenho dos estudantes brasileiros. São Paulo: Fundação Santillana, 2016.

PEREIRA, V. W. A predição na teia de estratégias de compreensão leitora. Revista

Confluência. Rio de Janeiro: Ed. Instituto de Língua Portuguesa, v. 1, p. 81-91, 2012.

. Arrisque-se... Faça o seu jogo. Letras de Hoje. Porto Alegre: EDIPUCRS, n. 128, v. 37, jun. 2002, p. 47-64.

SILVEIRA, Jane Rita Caetano da; FELTES, Heloisa Pedroso de Moraes. Pragmática e cognição: a textualidade pela relevância e outros ensaios. 2. ed. Caxias do Sul: EDUCS, 1999.

SMITH, F. Compreendendo a leitura. Porto Alegre: Artes Médicas, 2003.

SOLÉ, I. Estratégias de leitura. Porto Alegre: Artmed, 1998.

SPERBER, Dan; WILSON, Deirdre. Relevance: communication and cognition. 2 ed. Cambridge, USA: Blackwell, 1995.

WILSON, Deirdre; SPERBER, Dan. Teoria da relevância. Linguagem em (Dis)curso, v. 5, p. 221-268, set. 2010. Disponível em: <http://www.portaldeperiodicos.unisul.br/ index.php/Linguagem_Discurso/article/view/287/301>. Acesso em: 17 jun. 2018. 